\title{
Can we use endocan level to determine severity of pancreatitis?
}

\author{
A.R Baykan', I. Baydar², E. Şebin², Y. Ozdemir', S. Cerrah', B. Albayrak ${ }^{5}$, M. Senyurt ${ }^{3}$ \\ (1) Erzurum Regional Training and Research Hospital/ Gastroenterology Department ; (2) Gaziantep Islahiye Hospital/Internal Medicine Department ; (3) Erzurum Regional \\ Training and Research Hospital/Biochemistry Department ; (4) Erzurum Regional Training and Research Hospital/Gastrointestinal Surgery Department ; (5) Erzurum
} Ataturk University/Gastroenterology Department.

\begin{abstract}
Background and study aims : Endothelial cell specific molecule-1 (ESM-1), also known as endocan, is a soluble proteoglycan secreted by human vascular endothelial cells. In some studies, it has been found that endocan have important effects on cell adhesion, inflammation and angiogenesis. In this study, we aimed to evaluate the endocan level in patients with pancreatitis and the availability of endocan level in determining the severity of the disease.

Patients and methods : A total of 42 patients with pancreatitis and 33 healthy individuals were included in the study. The serum endocan levels in patients were evaluated 1st and 3 th days after the symptom's onset. Current scoring systems and the relationship between the severity of the disease and endocan levels were evaluated.

Results : The endocan levels of the patients on day 1 are significantly correlated only with the APACHE II score $(p=0.039$ $r=0.319$ ), while the endocan values on day 3 are significantly correlated with the BISAP (bedside index of severity in acute pancreatitis) $(p=0.013 r=0.380)$, APACHE II (Acute Physiology and Chronic Health Evaluation $)(p<0.001 ; r=0.53)$ and Ranson $(p=0.037$ $\mathbf{r}=\mathbf{0 . 3 2}$ ) scores. The cutoff level of endocan (day 3 ) was calculated $92.2 \mathrm{pg} / \mathrm{ml}(\mathbf{8 3} \%$ sensitivity and $\mathbf{5 0 \%}$ specificity; $\mathrm{p}=\mathbf{0 . 0 3 9}$ area under the curve 0.706 ) for severe pancreatitis when considering the patients with a score of 8 or higher in the APACHE II scoring system.

Conclusion : Serum endocan level can be used as a marker of prognosis in patients with pancreatitis. However, studies involving large populations are needed on this matter. (Acta gastroenterol. belg., 2021, 84, 321-325)
\end{abstract}

Key words : pancreatitis, endocan, pancreatitis score.

\section{Introduction}

Endothelial cell specific molecule-1 (ESM-1), also known as endocan, is a soluble proteoglycan secreted by human vascular endothelial cells $(50 \mathrm{kDa})$ (1). Endocan is an indicator of angiogenesis and endothelial cell activation in circulation. Endothelial adhesion and migration of the endocan to tissues is driven by adhesion molecules expressed in the activated endothelium. (such as vascular endothelial growth factor (VEGF): Intercellular Adhesion Molecule 1 (ICAM-1) : Leukocyte function-associated antigen (LFA-1)). VEGF plays a key role in angiogenesis because it maintains endothelial cell division and survival to improve vascular permeability. Endocan affects endothelial cells by facilitating the effects of VEGF-A on the receptor (VEGFR-2) and triggering endothelial permeability (2). Another important effect of the endocan is due to its binding with LFA-1 integrin. This leads to inhibition of the interaction with the endothelial ligand ICAM-1. As a result, it inhibits leukocyte diapedesis and demonstrates an antiinflammatory effect.

The prevalence of acute pancreatitis (AP) is approximately 50/100,000 people (3-4). It shows high mortality and morbidity rates. The severity of the disease is classified as mild, moderate and severe according to the revised Atlanta classification. The most common type is mild acute pancreatitis that is with no organ failure, local or systemic complications and usually improved in the first week. Moderate acute pancreatitis is defined by transient organ failure ( $<48$ hours), exacerbation of the co-morbid disease or the presence of local complications. And in severe acute pancreatitis, persistent organ failure ( $>48$ hours) is present (3). Severe acute pancreatitis is emerged in about $20 \%$ of affected patients (4). Several factors, including genetic, environmental and metabolic ones, increase the risk of severe acute pancreatitis (5).

Several clinical, laboratory and radiological scoring systems are used to predict the severity of pancreatitis. Some of these scoring systems predict the severity of the disease at the time of admission and some at the first 48-72 hours of the onset of the disease. However, these predictive models have low prediction because the prevalence of severe AP is low (6)

For different conditions, including some cancers (e.g. brain, lung, liver, kidney and urinary bladder), systemic inflammation and cardiovascular diseases, endocan has been reported that it can be used as a marker in analyses $(2,7-11)$. In our study, we aimed to determine whether blood endocan level could be used as a marker of the severity of the disease in patients with pancreatitis.

\section{Patients and methods}

The study was conducted in June-September 2017 period on 75 patients who admitted to the gastroenterology clinic of Erzurum Regional Training and Research Hospital with the diagnosis of acute pancreatitis. We aimed to determine the relationship between the severity of pancreatitis and serum endocan level, in patients with acute pancreatitis diagnosed in the gastroenterology clinic.

Correspondence to : Ahmed Ramiz Baykan. Phone : 00905555061878. Email : ahmedbaykan@hotmail.com

Submission date : 27/11/2019

Acceptance date : 21/09/2020 


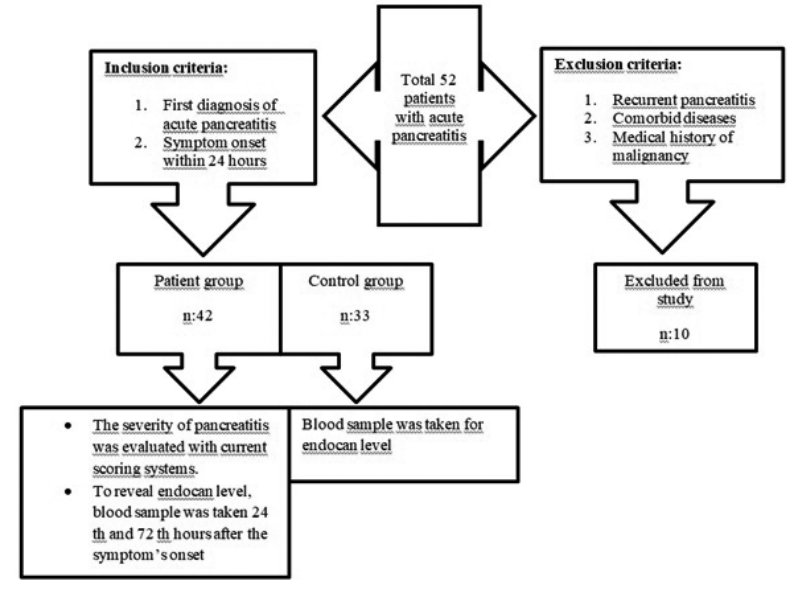

Fig. 1. - Flowchart.

Pancreatitis was diagnosed according to revised Atlanta criteria (3). Accordingly, the diagnosis is made when at least two of the three criteria are positive. These criteria include levels of amylase or lipase at least three times higher than normal, typical abdominal pain, or detection of pancreatitis findings on imaging.

Patients were included in our study if this was their first diagnosis of AP. Patients with a history of chronic concomitant diseases, medical history of malignancy and patients whose symptom onset exceeds 24 hours, were not included in the study. The control group consisted of 33 patients who presented to the gastroenterology outpatient clinic with nonspecific complaints, had no history of comorbid disease and had no disease based on their medical workups (figure 1).

Blood tests were based on fasting for at least 8 hours. Hemogram and biochemistry tests of the patients were ordered. To reveal endocan level, blood sample was taken 24 th and 72 th hours after the symptom's onset and for once for control group. Samples were stored at $-80^{\circ} \mathrm{C}$ and all analyzed at once to reveal the endocan level. Analyses were performed by the endocan/esm-1 ELISA kit ChemWell Fusion 4800 automatic ELISA analyzer.

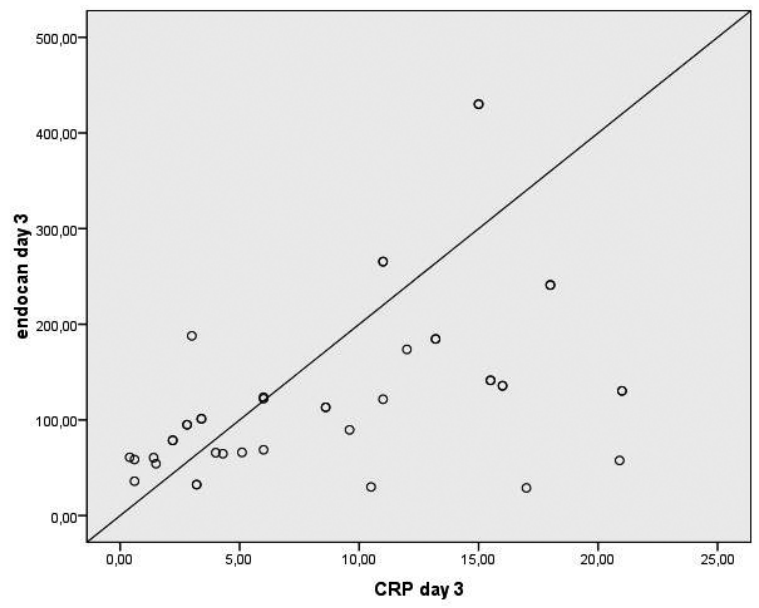

Fig. 2.
For the study, approval of the ethics committee for clinical researches of Erzurum Regional Training and Research Hospital was obtained (2017/08-63). SPSS version 17.0 was used for statistical evaluations. Numerical variables with normal distribution were shown as mean $\pm \mathrm{SD}$, whereas those without normal distribution were shown as mean (minimum - maximum). Categorical variables were shown as numbers and percentages. Mann-Whitney U and Kruskall-Wallis H tests were used for intergroup comparison of the numerical variables without normal distribution. Categorical variables were compared with $\chi^{2}$ and Fisher's exact $\chi^{2}$ tests. For the relationship between numerical variables, Pearson and Spearman correlation analysis was used. In order to determine severe pancreatitis, the receiver operating characteristics (ROC) curve was used to determine the endocan cutoff level.

\section{Results}

75 individuals were included in the study including 42 individuals with acute pancreatitis and 33 individuals in the control group. Demographic data of the patient and control groups are summarized in Table 1. Gender $(p=0.55)$, age $(p=0.1)$, triglyceride $(p=0.36)$, hematocrit $(p=0.88)$, BMI $(p=0.26)$, albumin $(p=0.06)$ values did not show a significant difference between the control and patient groups. WBC $(\mathrm{p}=<0.001), \mathrm{BUN}(\mathrm{p}=0.001)$, AST $(p=<0.001)$, CRP $(p=0.03)$, creatinine $(p=0.003)$ and endocan $(\mathrm{p}=0.013)$ values were found significantly high in the patient group. Mean hospital stay was 5,1 $\pm 2,3$ days

The etiology of pancreatitis was considered biliary in all patients. After imaging of stone in the common bile duct in 3 patients, ERCP (endoscopic retrograde cholangiopancreatography) was performed. None of the patients had post-ERCP pancreatitis or any other complication.

During evaluation of the relationship between endocan level and inflammation markers in patients with

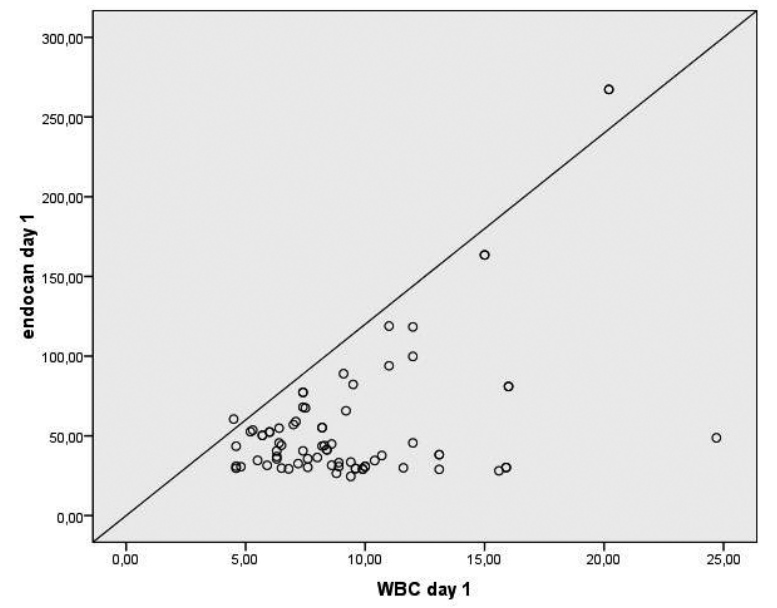

Fig. 3. 
Table 1. - Laboratory results and demographic data of the patients and control group

\begin{tabular}{|l|c|c|c|}
\hline & $\begin{array}{c}\text { Patient } \\
\text { Group n: 42 }\end{array}$ & $\begin{array}{c}\text { Control } \\
\text { Group n:33 }\end{array}$ & P value \\
\hline Gender (male) \% & $52.4(22)$ & $45.5(15)$ & 0.55 \\
\hline Age \pm SD & $60 \pm 19$ & $53 \pm 12$ & 0.1 \\
\hline CRP $(\mathrm{mg} / \mathrm{l})$ & $2.2 \pm 3.5$ & $1 \pm 0.6$ & $0.03^{*}$ \\
\hline WBC $\left(10^{\wedge} 9 / \mathrm{L}\right)$ & $11 \pm 4.2$ & $6.9 \pm 1.4$ & $<0.001^{*}$ \\
\hline Triglyceride $\pm \mathrm{SD}(\mathrm{mg} / \mathrm{dl})$ & $96 \pm 38$ & $103 \pm 30$ & 0.36 \\
\hline AST $\pm \mathrm{SD}(\mathrm{mg} / \mathrm{dl})$ & $223 \pm 224$ & $26 \pm 13$ & $<0.001^{*}$ \\
\hline Albumin $(\mathrm{g} / \mathrm{dl})$ & $3,9 \pm 0.4$ & $4.4 \pm 0.5$ & 0.06 \\
\hline Endocan $\pm \mathrm{SD}(\mathrm{pg} / \mathrm{ml})$ & $66 \pm 56$ & $43 \pm 14$ & $0.013^{*}$ \\
\hline Creatinine $\pm \mathrm{SD}(\mathrm{mg} / \mathrm{dl})$ & $0.8 \pm 0.3$ & $0.6 \pm 0.2$ & $0.003^{*}$ \\
\hline Hematocrit $\pm \mathrm{SD}(\%)$ & $43.5 \pm 5.2$ & $43.7 \pm 5.6$ & 0.88 \\
\hline BUN $\pm \mathrm{SD}(\mathrm{mg} / \mathrm{dl})$ & $16 \pm 11.8$ & $7 \pm 3.4$ & $0.001^{*}$ \\
\hline BMI & $23.9 \pm 3.1$ & $24.8 \pm 3.2$ & 0.26 \\
\hline
\end{tabular}

Abbreviations : CRP, C- reactive protein ; WBC, White blood cell ; AST, aspartate aminotransferase ; BUN, blood urea nitrogen ; BMI, body mass index ; * $\mathrm{P}<0.05$ is considered significant for statistical analyses.

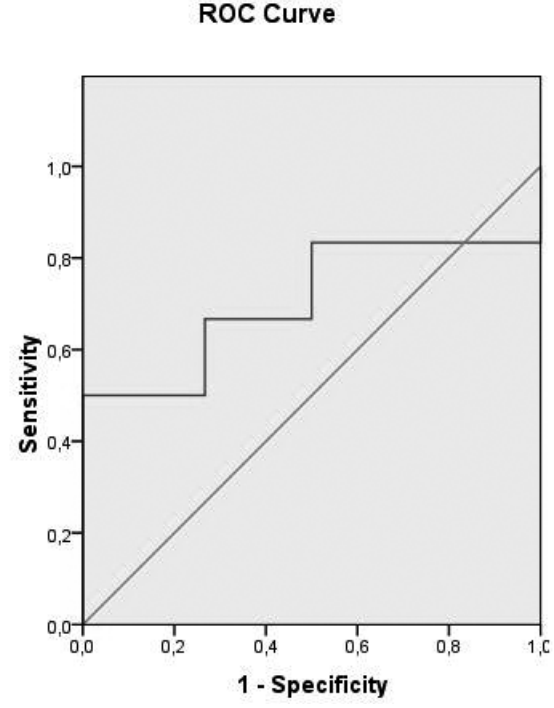

Fig. 4.

Table 2. - Patient numbers and current pancreatitis scores

\begin{tabular}{|c|c|c|c|c|c|c|c|c|}
\hline & \multicolumn{2}{|l|}{ BISAP } & \multicolumn{2}{|l|}{ RANSON } & \multicolumn{2}{|l|}{ APACHE II } & \multicolumn{2}{|l|}{ IMRIE } \\
\hline & Number of patients & $\%$ & Number of patients & $\%$ & Number of patients & $\%$ & Number of patients & $\%$ \\
\hline 0 & 5 & 11.9 & & & & & 6 & 8 \\
\hline 1 & 7 & 16.7 & 5 & 6.7 & 1 & 2.4 & 17 & 22.7 \\
\hline 2 & 16 & 38.1 & 17 & 22.7 & 4 & 9.5 & 10 & 13.3 \\
\hline 3 & 14 & 33.3 & 13 & 17.3 & 3 & 7.1 & 5 & 6.7 \\
\hline 4 & & & 5 & 6.7 & 6 & 14.3 & 2 & 2.7 \\
\hline 5 & & & 2 & 2.7 & 3 & 7.1 & 2 & 2.7 \\
\hline 6 & & & & & 5 & 11.9 & & \\
\hline 7 & & & & & 8 & 19 & & \\
\hline 8 & & & & & 6 & 14.3 & & \\
\hline 9 & & & & & 1 & 2.4 & & \\
\hline 10 & & & & & 5 & 11.9 & & \\
\hline
\end{tabular}

Abbreviations : BISAP, Bedside Index of Severity in Acute; APACHE 2, Acute Physiology And Chronic Health Evaluation II.

Table 3. - Correlation between the endocan level and the pancreatitis severity scales on the 1st and 3rd day of the patients

\begin{tabular}{|l|c|c|c|c|}
\hline \multirow{2}{*}{} & \multicolumn{2}{|c|}{ Endocan day 1} & \multicolumn{2}{c|}{ Endocan day 3 } \\
\cline { 2 - 5 } & $\mathrm{p}$ value & $\mathrm{r}$ & $\mathrm{p}$ value & $\mathrm{r}$ \\
\hline APACHE II & $0.039^{*}$ & 0.31 & $<0.001^{*}$ & 0.53 \\
\hline BISAP & 0.75 & 0.27 & $0.013^{*}$ & 0.38 \\
\hline RANSON & 0.39 & 0.134 & $0.037^{*}$ & 0.32 \\
\hline IMRIE & 0.58 & 0.087 & 0.38 & 0.13 \\
\hline CRP day 1 & 0.39 & 0.13 & & \\
\hline CRP day 3 & - & - & $0.002^{*}$ & 0.46 \\
\hline WBC day 1 & $<0.001 *$ & 0.506 & - & - \\
\hline WBC day 3 & - & - & 0.057 & 0.29 \\
\hline
\end{tabular}

Abbreviations : APACHE 2, Acute Physiology And Chronic Health Evaluation II ; BISAP, Bedside Index of Severity in Acute ; CRP, Creactive protein ; WBC, White blood cell ; * $\mathrm{P}<0.05$ is considered significant for statistical analyses.

pancreatitis, a significant correlation was found between the endocan level tested at hospitalization and WBC $(\mathrm{r}=0.47, \mathrm{p}=0.001)$ and this relationship was positive but not significant when compared with CRP. There was a significant correlation between the endocan and CRP levels and the levels tested on day 3, while positive correlation with WBC was not found significant $(\mathrm{r}=0.46$ $\mathrm{p}=0.002 ; \mathrm{r}=0.29 \mathrm{p}=0.057$ respectively) (figure 2-3).

We compared the severity of pancreatitis with various severity scales (APACHE, BISAP, Ranson and Imrie) that are common today. The number of patients and the pancreatitis severity score are shown in table 2-3. In our study, the endocan levels of the patients on day 1 are significantly correlated only with the APACHE II score $(p=0.039 \mathrm{r}=0.319)$, while the endocan values on day 3 are significantly correlated with the BISAP (bedside index of severity in acute pancreatitis) $(\mathrm{p}=0.013 \mathrm{r}=0.380)$, APACHE II (Acute Physiology and Chronic Health Evaluation) $(\mathrm{p}<0.001 ; \mathrm{r}=0.53)$ and Ranson $(\mathrm{p}=0.037$ $\mathrm{r}=0.32$ ) scores. It was correlated with Imrie scoring but was not significant.

Finally, the cutoff level of day 3 endocan level was calculated $92.2 \mathrm{pg} / \mathrm{ml}(83 \%$ sensitivity and $50 \%$ 
specificity; $p=0.039$ area under the curve 0.706 ) for severe pancreatitis when considering the patients with a score of 8 or higher with a significantly increased mortality in the APACHE II scoring system (figure 4).

\section{Discussion:}

Endocan levels of patients with pancreatitis were tested in our study. Comparison was made with actual scoring systems that evaluate the severity of pancreatitis and the endocan levels on day 1 were found significantly correlated only with the APACHE II score while the endocan values on day 3 were found significantly correlated with the BISAP, APACHE II and RANSON scores.

Li et al. in their study (12), they stated that the ranson score showed the severity of the disease better in elderly patients. In our evaluation with endocan, we did not find a significant difference with the ranson score compared to younger patients. Through many years of practice, APACHE II has been the most widely used AP scoring system, and it is recommended in a number of guidelines $(13,14)$. Further studies comparing the severity of pancreatitis suggest that it evaluates prognosis better compared to other scoring systems $(15,16)$. APACHE II score is also an important parameter which is frequently used for intensive care and indicates prognosis. We could not find a publication similar to our study regarding patients with pancreatitis. However as in pancreatitis, the endocan level of patients with sepsis, another condition in which the inflammatory cascade was intensely triggered, was significant in showing the prognosis of the disease (using the APACHE II scoring system for disease severity) (17-19).

Most of the scoring systems currently available require analysis of many parameters. In a study involving 18256 patients with acute pancreatitis, the medical histories of patients were examined and the APACHE scoring system could be assessed only in $2.2 \%$ of all patients (20). Moreover, two other commonly used parameters, Ranson and Glascow scales, require 48 hours to full assessment. Predicting the prognosis early is important to guide treatment in AP. Hence, there is a need for a marker to be used in daily practice to demonstrate the severity of the AP. Therefore, many markers such as adipokines (21), D-dimer (22,23), matrix metalloproteinases 2 and 9 (24), visfatin (25), amylase and body mass index score (26), apolipoprotein B to apolipoproein A1 ratio (27) have been used to determine the prognosis of the disease in the early period.

WBC, one of the inflammation markers, is used in many scoring systems of pancreatitis such as RANSON, APACHE II and BISAP. However, affection of WBC from many physical variables such as medication, hydration and pregnancy poses a disadvantage to determine the severity of the disease in patients with pancreatitis (28). CRP, another inflammatory marker, is less affected by external factors and the only biomarker which has been used widely (29). CRP is limited by its delay in attaining the peak value after onset of symptoms which is up to 72 hours (30). Kylanpaa et al. showed sensitivity of CRP only $37 \%$ at admission (31). In our study CRP levels were evaluated at 24th and 72th hours after the symptom onset and CRP levels on 72th hour found correlated with endocan levels.

Albumin is a negative acute phase reactant and serum albumin level has been associated with increased mortality in acutely ill patients in previous reports (32). CRP / Albumin ratio is another cheap, repeatable marker used to evaluate the severity of pancreatitis. It was found that an increase of 1 unit in the CRP/ albumin ratio resulted in an increase of 1.52 times in mortality risk (33). In our study, the CRP/ albumin ratio was significantly higher in the patient group compared to the control group. However, pancreatitis is a dynamic process and albumin is affected by many factors. Large, multicenter studies are required to confirm results and establish the serum $\mathrm{CRP} /$ albumin ratio as a useful marker for the prediction of prognosis for pancreatitis.

The BUN is an important prognostic marker for the assessment of severe AP (34) and also used in some scoring systems. BUN values above $20 \mathrm{mg} / \mathrm{dl}$ were found to be associated with increased mortality. However, the issue of when to measure BUN values to evaluate the severity of pancreatitis has not been clarified. In the study including 1612 patients with acute pancreatitis, the increase in BUN value in the first 24 hours was accompanied by htc $>44 \%$ in the application. The most accurate in predicting persist organ failure and pancreatic necrosis, outperforming APACHE II score (35). In our study, the BUN values in the patient group were significantly higher than the control group. In addition, it was observed that BUN values showed a significant positive correlation with APACHE 2 score and endocan on the first day.

Endocan has been used as an inflammatory marker for diseases such as sepsis, pneumonia, acute respiratory distress syndrome (ARDS), atherosclerosis due to its effects on vascular permeability, angiogenesis and leukocyte diapedesis, and significant results have been obtained (8,9,36-38). Accordingly, we hypothesized that serum endocan levels can be used as a marker to predict the severity of the disease in patients with pancreatitis with intense inflammatory response. As a result, the endocan levels were observed significantly correlated with APACHE II, one of the scoring systems of pancreatitis, on days 1 and 3 while the CRP levels were found correlated BISAP and RANSON scores only on day 3 .

The absence of serum CRP levels being tested at the 48th hour of hospitalization, the low number of patients with severe pancreatitis and almost all etiology of pancreatitis are of biliary origin are among limitations of our study. 


\section{Conclusion:}

To the best of our knowledge, there is no study on endocan, which evaluates the severity of pancreatitis. We conclude that serum endocan level can be used as a marker of prognosis in patients with pancreatitis. However, studies involving large populations are needed on this matter.

\section{Conflict of interest statement}

There is no conflict of interest to declare

\section{References}

1. BAGHY K, TÁTRAI P, REGÖS E, KOVALSZKY I. Proteoglycans in liver cancer. World Journal of Gastroenterology, 2016, 22 : 379-93.

2. LEE HG, CHOI HY, BAE JS. Endocan as a potential diagnostic or prognostic biomarker for chronic kidney disease. Kidney International, 2014, 86 : 1079 81.

3. BANKS PA, BOLLEN TL, DERVENIS C, GOOSZEN HG, JOHNSON CD, SARR MG, et al. Classification of acute pancreatitis - 2012 : Revision of the Atlanta classification and definitions by international consensus. Gut, 2013, 62: $102-11$

4. BOLLEN TL. Acute pancreatitis: International classification and nomen clature, Clinical Radiology, 2016, 71 : 121-33.

5. WHITCOMB DC. Genetic risk factors for pancreatic disorders. Gastroenterology. 2013, $144:$ 1292-302.

6. ROBERT JH, FROSSARD JL, MERMILLOD B, SORAVIA C, MENSI N, ROTH M, et al. Early prediction of acute pancreatitis : Prospective study comparing computed tomography scans, Ranson, Glasgow, Acute Physiology and Chronic Health Evaluation II scores, and various serum markers. World Journal of Surgery, 2002, $26: 612-9$

7. KUNDI H, GOK M, KIZILTUNC E, TOPCUOGLU C, CETIN M, CICEKCIOGLU H, et al. The Relationship between Serum Endocan Levels with the Presence of Slow Coronary Flow : A Cross-Sectional Study. Clin Appl. Thromb., 2017, 23 : 472-7.

8. BALTA S, MIKHAILIDIS DP, DEMIRKOL S, OZTURK C, CELIK T, IYISOY A. Endocan : A novel inflammatory indicator in cardiovascular disease? Atherosclerosis, 2015, $243: 339-43$.

9. PERROTTI A, CHENEVIER-GOBEAUX C, ECARNOT F, BARDONNET $\mathrm{K}$, BARRUCAND B, FLICOTEAUX G, et al. Is Endocan a Diagnostic Marker for Pneumonia After Cardiac Surgery? The ENDOLUNG Study. Ann. Thorac. Surg., 2018, $105: 535-41$.

10. MUSIALOWSKA D, ZBROCH E, KOC-ZORAWSKA E, MUSIALOWSKI $\mathrm{P}$, MALYSZKO J. Endocan Concentration in Patients With Primary Hypertension. Angiology., 2018, 69 : 483-9.

11. LALOGLU E, KUMTEPE Y, AKSOY H, TOPDAGI YILMAZ EP. Serum endocan levels in endometrial and ovarian cancers. J. Clin. Lab. Anal., 2017, 31 : e22079

12. LI Y, ZHANG J, ZOU J. Evaluation of four scoring systems in prognostication of acute pancreatitis for elderly patients. BMC Gastroenterol., 2020, 20 : 165

13. GURUSAMY KS, FAROUK M, TWEEDIE JH. UK guidelines for management of acute pancreatitis : Is it time to change? Gut, 2005, $54: 1344-5$.

14. BANKS PA, FREEMAN ML, FASS R, BARONI DS, MUTLU EA, BERNSTEIN DE, et al. Practice guidelines in acute pancreatitis. Am. J. Gastroenterol., 2006, $101: 2379-400$.

15. HARSHIT K, SINGH G. A Comparison of APACHE II, BISAP, Ranson's Score and Modified CTSI in Predicting the Severity of Acute Pancreatitis Based on the 2012 Revised Atlanta Classification. Gastroenterol. Rep., 2018 $6: 127-31$

16. CHO JH, KIM TN, CHUNG HH, KIM KH. Comparison of scoring systems in predicting the severity of acute pancreatitis. World J. Gastroenterol., 2015 , $21: 2387-94$.

17. ZHANG Q, LI C. Risk stratification and prognostic evaluation of endothelial cell-specific molecule1, von Willebrand factor, and a disintegrin-like and metalloprotease with thrombospondin type 1 motif for sepsis in the emergency department : An observational study. Exp. Ther.Med., 2019, 17 : 4527-35

18. MIHAJLOVIC DM, LENDAK DF, BRKIC S V., DRASKOVIC BG, MITIC GP, NOVAKOV MIKIC AS, et al. Endocan is useful biomarker of survival and severity in sepsis. Microvasc. Res., 2014, 93 : 92-7.

19. PAULY D, HAMED S, BEHNES M, LEPIORZ D, LANG S, AKIN I, et al. Endothelial cell-specific molecule-1/endocan: Diagnostic and prognostic value in patients suffering from severe sepsis and septic shock. J. Crit. Care., 2016, $31: 68-75$.

20. WU BU, JOHANNES RS, SUN X, TABAK Y, CONWELL DL, BANKS PA The early prediction of mortality in acute pancreatitis : A large populationbased study. Gut., 2008, 57 : 1698-703.

21. KARPAVICIUS A, DAMBRAUSKAS Z, GRADAUSKAS A, SAMUILIS A, ZVINIENE K, KUPCINSKAS J, et al. The clinical value of adipokines in predicting the severity and outcome of acute pancreatitis. BMC Gastroenterol., 2016, $16: 99$

22. WAN J, YANG X, HE W, ZHU Y, ZHU Y, ZENG H, et al. Serum D-dime levels at admission for prediction of outcomes in acute pancreatitis. BMC Gastroenterol., 2019, $19: 67$.

23. ZHANG GQ, WANG G, LI L, HU JS, JI L, LI YL, et al. Plasma D-dimer level is an early predictor of severity of acute pancreatitis based on 2012 Atlanta classification. Med. Sci. Monit., 2019, 25 : 9019-27.

24. NAWACKI L, GRABOWSKA U, GŁUSZEK S. Can the matrix metalloproteinases 2 and 9 predict the course of acute pancreatitis in previously healthy patients? Acta Gastroenterol. Belg., 2019, 82 : 501-5.

25. SCHÄFFLER A, HAMER OW, DICKOPF J, GOETZ A, LANDFRIED $\mathrm{K}$, VOELK M, et al. Admission visfatin levels predict pancreatic and peripancreatic necrosis in acute pancreatitis and correlate with clinical severity. Am. J. Gastroenterol., 2011, 106 : 957-67.

26. ZHENG L, HONG W, GENG W, STOCK S, PAN J. A comparison of the BISAP score and Amylase and BMI (CAB) score versus for predicting severe acute pancreatitis. Acta Gastroenterol. Belg., 2019, 82 : 397-400.

27. WU J, WANG Y, LI H, TAN W, CHEN X, YE S. Serum apolipoprotein B-toapolipoprotein A1 ratio is independently associated with disease severity in patients with acute pancreatitis. Sci. Rep., 2019, $9: 7764$

28. QI X, YANG F, HUANG H, DU Y, CHEN Y, WANG M, et al. A reduced lymphocyte ratio as an early marker for predicting acute pancreatitis. Sci. Rep., 2017, $7: 44087$

29. MATULL WR, PEREIRA SP, O'DONOHUE JW. Biochemical markers of acute pancreatitis. Journal of Clinical Pathology, 2006, 59 : 340-4.

30. HAGJER S, KUMAR N. Evaluation of the BISAP scoring system in prognostication of acute pancreatitis - A prospective observational study. Int J. Surg., 2018, 54 : 76-81.

31. KYLÄNPÄÄ-BÄCK ML, TAKALA A, KEMPPAINEN E, PUOLAKKAINEN P, HAAPIAINEN R, REPO H. Procalcitonin strip test in the early detection of severe acute pancreatitis. Br. J. Surg., 2001, 88 : 222-7.

32. VINCENT J-L, DUBOIS M-J, NAVICKIS RJ, WILKES MM. Hypoalbuminemia in Acute Illness : Is There a Rationale for Intervention? Ann. Surg., 2003, $237: 319-34$.

33. KAPLAN M, ATES I, AKPINAR MY, YUKSEL M, KUZU UB, KACAR S, et al. Predictive value of C-reactive protein/albumin ratio in acute pancreatitis. Hepatobiliary Pancreat. Dis. Int., 2017, 16 : 424-30.

34. ZHOU H, MEI X, HE X, LAN T, GUO S. Severity stratification and prognostic prediction of patients with acute pancreatitis at early phase : A retrospective study. Medicine (Baltimore), 2019, 98 : e15275.

35. KOUTROUMPAKIS E, WU BU, BAKKER OJ, DUDEKULA A, SINGH VK, BESSELINK MG, et al. Admission hematocrit and rise in blood urea nitrogen at $24 \mathrm{~h}$ outperform other laboratory markers in predicting persistent organ failure and pancreatic necrosis in acute pancreatitis : A post hoc analysis of three large prospective databases. American Journal of Gastroenterology, 2015, $110:$ 1707-16.

36. HSIAO SY, KUNG C TE, TSAI NW, SU CM, HUANG CC, LAI YR, et al. Concentration and value of endocan on outcome in adult patients after severe sepsis. Clin. Chim. Acta, 2018, $483: 275-80$.

37. ZHAO R, DONG S. Clinical value of serum endocan and procalcitonin in early diagnosis and prognosis evaluation of sepsis. Zhonghua Wei Zhong Bing Ji Jiи Yi Хиe. 2017, 29 : 321-6.

38. DE FREITAS CAIRES N, GAUDET A, PORTIER L, TSICOPOULOS A, MATHIEU D, LASSALLE P. Endocan, sepsis, pneumonia, and acute respiratory distress syndrome. Critical Care, 2018, $22: 280$. 